\title{
Studi Perencanaan Pola Operasi Waduk RanduguntingKabupaten Blora, Provinsi Jawa Tengah Guna Kebutuhan Air Irigasi
}

\author{
Junario Vito Ardana', Satrio Sinung Nugroho', \\ Budi Santosa $^{3}$, Daniel Hartanto ${ }^{4}$ \\ email: ${ }^{2}$ satriosinung23@gmail.com
}

Program Studi Teknik Sipil, Fakultas Teknik, Unika Soegijapranata, Semarang, Universitas Katolik Soegijapranata; Jl. Pawiyatan Luhur IV/1 Bendan Dhuwur Semarang 50234, 024-8441555

\begin{abstract}
Abstrak
Pengolahan air di waduk menjadi hal yang sangat penting karena dalam pemanfaatannya perlu perencanaan dan pengoperasian yang tepat dan efisien. Tujuan dari penelitian adalah menghitung debit ketersediaan dan kebutuhan air, kapasitas tampungan efektif serta melakukan simulasi pola pengoperasian dari Waduk Randugunting.

Hasil analisis didapat debit andalan berkisar dari 0,07 m3/detik hingga 33,67 m3/detik. Sedangkan dari hasil analisis debit kebutuhan air irigasi dengan pola tanam existing dengan luas DI 1.595 ha, didapat debit maksimum sebesar 2,07 m3/detik. Hasil simulasi dengan pola tanam existing selama 30 tahun (2010-2039) didapat persentase keberhasilan periode 99,86\%.
\end{abstract}

Kata kunci : Waduk, Simulasi Pola Operasi, FJ. Mock

\section{Abstract}

Water treatment in reservoirs is very important because in its utilization it needs proper and efficient planning and operation. The purpose of this research is to calculate the discharge of water availability and demand, effective storage capacity and to simulate the operation pattern of the Waduk Randugunting.

Mainstay discharge analysis results obtained ranged from $0,07 \mathrm{~m} 2 / \mathrm{s}$ to $33,67 \mathrm{~m} 2 / \mathrm{sec}$. While the results of the analysis of discharge water irrigation with cropping pattern existing with an area of 1.595 ha DI, obtained maximum flow of 2,07 $\mathrm{m2} / \mathrm{sec}$. The simulation results with cropping patterns existing for 30 years (2010-2039) obtained a success percentage of 99,86\%.

Keywords: Reservoir, Operation Pattern Simulation, FJ. Mock

\section{PENDAhUluAN}

Sumber daya air menjadi komponen penting dalam kehidupan manusia, Salah satunya untuk kebutuhan air irigasi untuk sektor pertanian. Sektor pertanian menjadi penunjang pemenuhan kebutuhan pangan penduduk. Sedangkan penduduknya dari waktu ke waktu terus meningkat dan diikuti dengan peningkatan sektor lainnya. Hal ini mengakibatkan menurunnya kualitas dan kuantitas air, terutama akibat berbagai macam kegiatan manusia yang berhubungan dengan penggunaan air.

Permasalahan akan ketersediaan air sangat berpengaruh saat musim kemarau, dimana beberapa daerah di Jawa Tengah seringkali kekurangan sumber 
daya air untuk memenuhi kebutuhan sehari-hari. Pengelolaan air merupakan hal yang sangat penting melihat dari pemanfaatan dan ketersediaannya, perlu perencanaan dan manajemen air yang efisien dan tepat, oleh karena itu perencanaan dan pengoperasian waduk yang tepat sangat dibutuhkan (Mythili, 2013).

Waduk Randugunting di Kabupaten Blora memiliki fungsi untuk penyedia air irigasi, penyedia air baku dan pembangkit listrik. Penelitian ini dimaksudkan untuk menganalisis debit ketersediaan dan kebutuhan air berdasarkan pola tanam existing. Sehingga berdasarkan analisis tersebut didapat alternatif masa tanam, pola pengoperasian waduk dan pengembangan daerah irigasi.

\section{TINJAUAN PUSTAKA}

Untuk mencapai tujuan penelitian, digunakan beberapa teori, berikut adalah teori yang digunakan.

\section{Curah Hujan Kawasan (Polygon Thiessen)}

Metode polygon Thiessen dilakukan dengan menghitung bobot dari masing-masing pos stasiun hujan, dimana daerah yang terbentuk dianggap mewakili luasan di sekitarnya. Berikut rumus yang digunakan untuk menghitung curah hujan kawasan:

$R=\frac{A_{1} \cdot P_{1}+A_{2} \cdot P_{2}+\ldots+A_{n} \cdot P_{n}}{A_{1}+A_{2}+\ldots+A_{n}}$

Keterangan:

$\mathrm{R}=$ curah hujan kawasan (mm)

$\mathrm{R}_{\mathrm{n}}=$ curah hujan ditiap titik pengamatan (mm)

$\mathrm{A}_{\mathrm{n}}=$ luas area yang mewakili tiap stasiun hujan $\left(\mathrm{km}^{2}\right)$

\section{Analisis Klimatologi (Penman Monteith)}

Analisis ini digunakan untuk menghitung evapotranspirasi $\left(\mathrm{ET}_{0}\right)$, terdapat beberapa unsur klimatologi yang diperlukan dalam analisis ini, yaitu temperatur udara $(\mathrm{T})$, kelembaban relatif (RH), kecepatan angin (U), penyinaran matahari (Rn). Berikut rumus yang digunakan untuk menghitung $\mathrm{ET}_{0}$ :

$$
E T_{0}=C \times(W \times R n+(1-W) \times(e s-e a) \times
$$$$
f(U)
$$

Keterangan:

$\mathrm{Et}_{0}=$ evapotranspirasi tanama (mm/hari)

$\mathrm{C}=$ angka koreksi Penman

$\mathrm{W}=$ faktor pemberat pengaruh penyinaran matahari pada $\mathrm{ET}_{0}$

$\mathrm{Rn}=$ radiasi matahari netto (permukaan tanaman ( $\mathrm{mm} /$ hari)

$1-\mathrm{W}=$ faktor pemberat untuk pengaruh kecepatan angin dan kelembaban

es-ea = perbedaan tekanan uap air jenuh pada suhu udara rata-rata dengan tekanan uap air nyata rata-rata di udara $(\mathrm{kPa})$

$\mathrm{U} \quad=$ kecepatan angin $(\mathrm{km} / \mathrm{hari})$

$\mathrm{f}(\mathrm{U})=$ fungsi pengaruh angin pada $\mathrm{ET}_{0}$ (km/hari)

\section{Analisis Ketersediaan Air (FJ. Mock)}

Berikut merupakan tahapan analisis debit ketersediaan dengan metode FJ. Mock:

a. Perhitungan curah hujan harian

b. Perhitungan evapotranspirasi terbatas (ET)

c. Analisis hidrologi

1. Faktor bukaan lahan

2. Luas DAS

3. Kapasitas kelembaban tanah (SMC)

d. Keseimbangan air pada permukaan tanah

e. Simpanan air bawah permukaan

1. Perhitungan laju infiltrasi

2. Kandungan air tanah

3. Faktor resesi aliran tanah

f. Aliran sungai 
1. Aliran air tanah

2. Aliran langsung

3. Aliran permukaan

\section{Bangkitan Data Inflow (Thomas Fiering)}

Metode ini digunakan sebagai solusi kurang panjangnya data curah hujan, maka dengan metode ini dapat memproyeksikan data hujan untuk beberapa tahun kedepan. Berikut rumus yang digunakan:

$Q_{i+1, j}=Q_{i}+b_{j}\left(Q_{i, j-1}-Q_{j-1}\right)+t_{i} S d_{j}(1-$ $\left.\left.\boldsymbol{r}_{j}\right)^{2}\right)^{0,5}$

Keterangan:

$\mathrm{Q}_{\mathrm{i}+1, \mathrm{j}}=$ debit hasil pembangkitan untuk periode $j$ dan tahun ke $i+1$

$\mathrm{Q}_{i, j-1}=$ debit pada tahun ke $i$, pada periode sebelumnya $(j-1)$

$\mathrm{r}_{\mathrm{j}} \quad=$ koefisien korelasi antara debit periode sebelumnya $(j-1)$ dan periode $j$

$b_{j} \quad=$ koefisien regresi antara debit periode $j$ dan periode sebelumnya $(j-1)$

$\mathrm{t}_{\mathrm{i}} \quad=$ bilangan random normal

$\mathrm{Sd}_{\mathrm{j}} \quad=$ standar deviasi periode $j$

Analisis Kebutuhan Air Irigasi

Kebutuhan air irigasi merupakan jumlah volume air yang digunakan untuk memenuhi kebutuhan tanaman. Kebutuhan air irigasi sangat berkaitan dengan pola tanam dan penjadwalan masa tanam. Berikut rumus yang digunakan:

a. Kebutuhan air irigasi untuk tanaman padi

$N F R=E T c+P r-R e+W L R$

b. Kebutuhan air irigasi untuk tanaman palawija

$$
N F R=E T c-R e
$$

Keterangan:

NFR = kebutuhan air sawah $(\mathrm{mm} / \mathrm{hari})$

ETc $=$ kebutuhan air konsumtif (mm/hari)

Pr = kehilangan air akibat perkolasi (mm/hari)

$$
\begin{aligned}
\mathrm{Re} & =\text { curah hujan efektif (mm/hari) } \\
\mathrm{WLR} & =\text { penggantian lapisan air } \\
& \text { (mm/hari) }
\end{aligned}
$$

\section{Simulasi Tampungan Waduk}

Simulasi operasi waduk dilakukan dengan tujuan untuk meninjau seberapa besar peluang keandalan dan kegagalan yang terjadi pada suatu sistem pengoperasian waduk dalam memenuhi kebutuhan air.

\section{METODE PENELITIAN Diagram Alir Penelitian}

Berikut adalah diagram alir penelitian secara umum, untuk lebih jelas dapat dilihat pada Gambar 1.

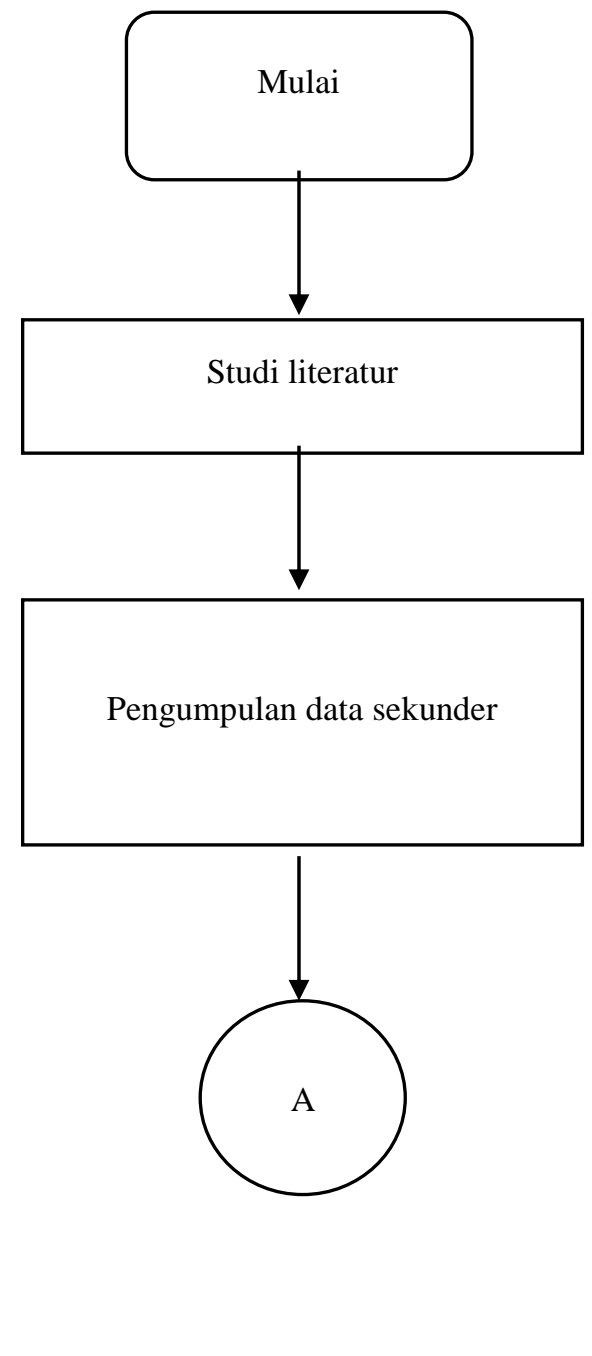




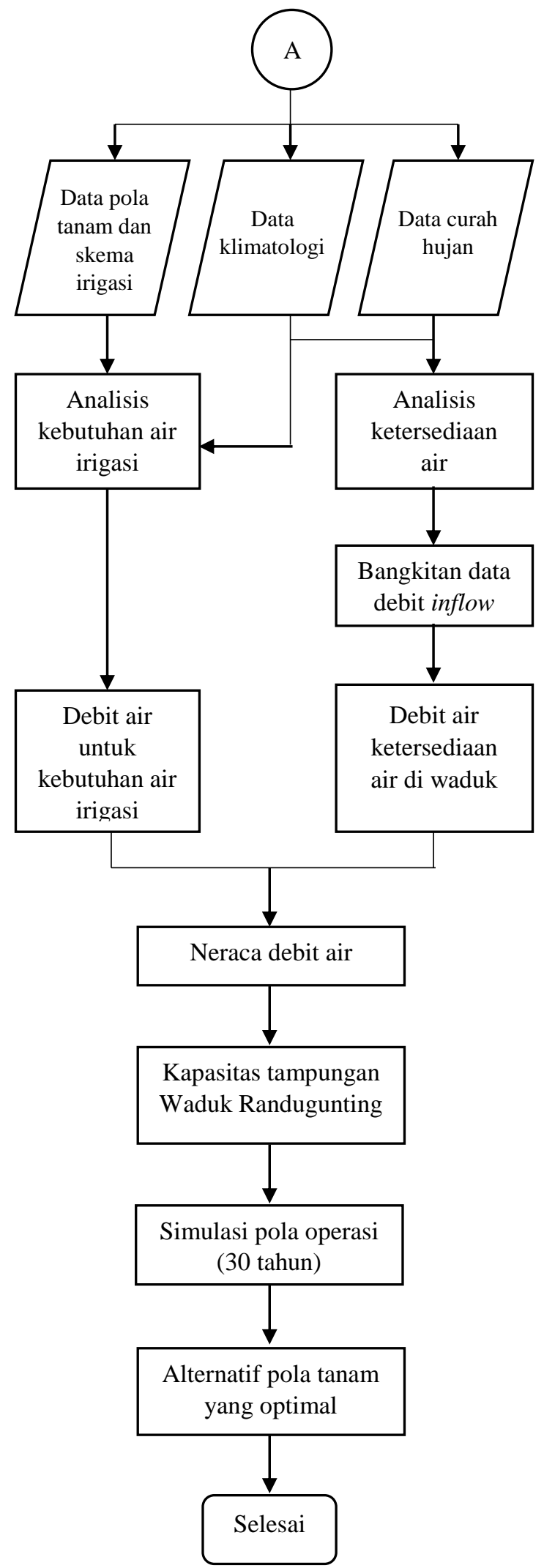

\section{Lokasi Studi}

Waduk Randugunting terletak pada Desa Kalinanas, Kabupaten Blora, Provinsi Jawa Tengah dengan koordinat $6^{\circ} 52^{\prime} 19,14^{\prime \prime}$ LS dan $111^{\circ} 15^{\prime} 30,20^{\prime \prime}$ BT. Untuk lebih jelas dapat dilihat pada Gambar 2.

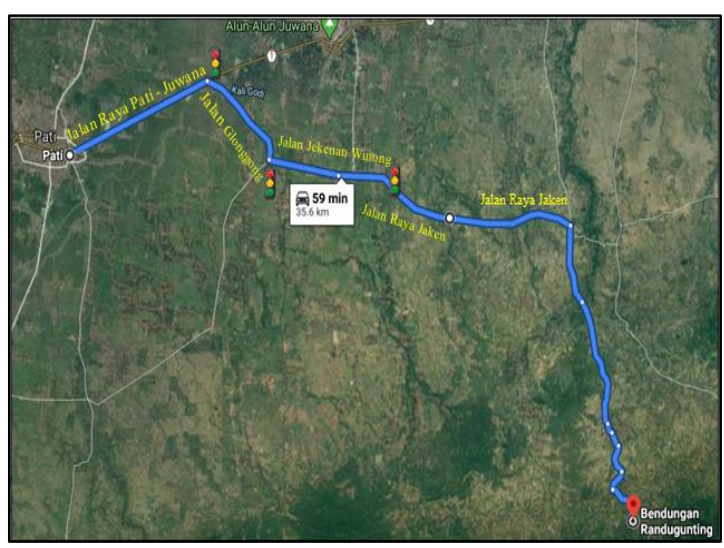

Gambar 2. Peta Lokasi Waduk Randugunting

\section{HASIL DAN PEMBAHASAN Analisis Debit Ketersediaan Air Metode F.J Mock}

Pada analisis ini, digunakan hasil analisis sebelumnya yaitu:

a. Hasil analisis curah hujan kawasan, digunakan dua stasiun hujan yaitu Stasiun Todanan dan Stasiun Tunjungan dengan panjang data hujan 10 tahun $(2010-2019)$.

b. Hasil analisis evapotranspirasi $\left(\mathrm{ET}_{0}\right)$, digunakan data klimatologi dari Stasiun Klimatologi Tempuran dengan panjang data empat tahun (2011 - 2014).

c. Digunakan hasil analisis berdasarkan kondisi lapangan diantaranya yaitu, jumlah hari hujan yang didapat dari data curah hujan, kondisi vegetasi penutup lahan, koefisien infiltrasi dan resesi.

Gambar 1. Alir Pengerjaan Penelitian 
Hasil dari analisis tersebut didapat debit yang tersedia pada DAS

Randugunting, untuk hasilnya dapat

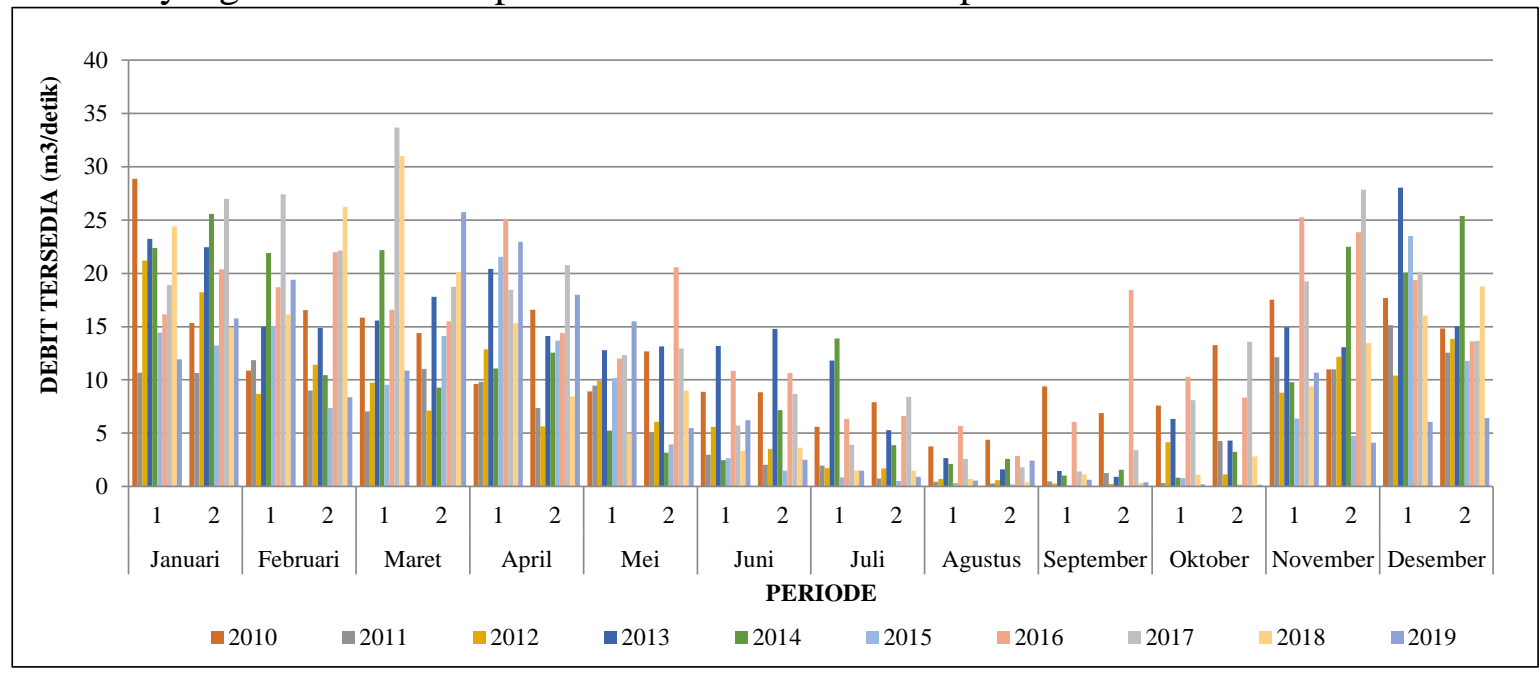

Gambar 3. Grafik Debit Ketersediaan Air Tahun 2010 - 2019

Analisis Bangkitan Data Debit Inflow Metode Thomas Fiering

Metode ini digunakan untuk memperpanjang data untuk beberapa tahun kedepan. Berikut adalah hasil analisis bangkitan data debit inflow untuk 20 tahun kedepan (2020 - 2039), dapat dilihat pada Gambar 4.

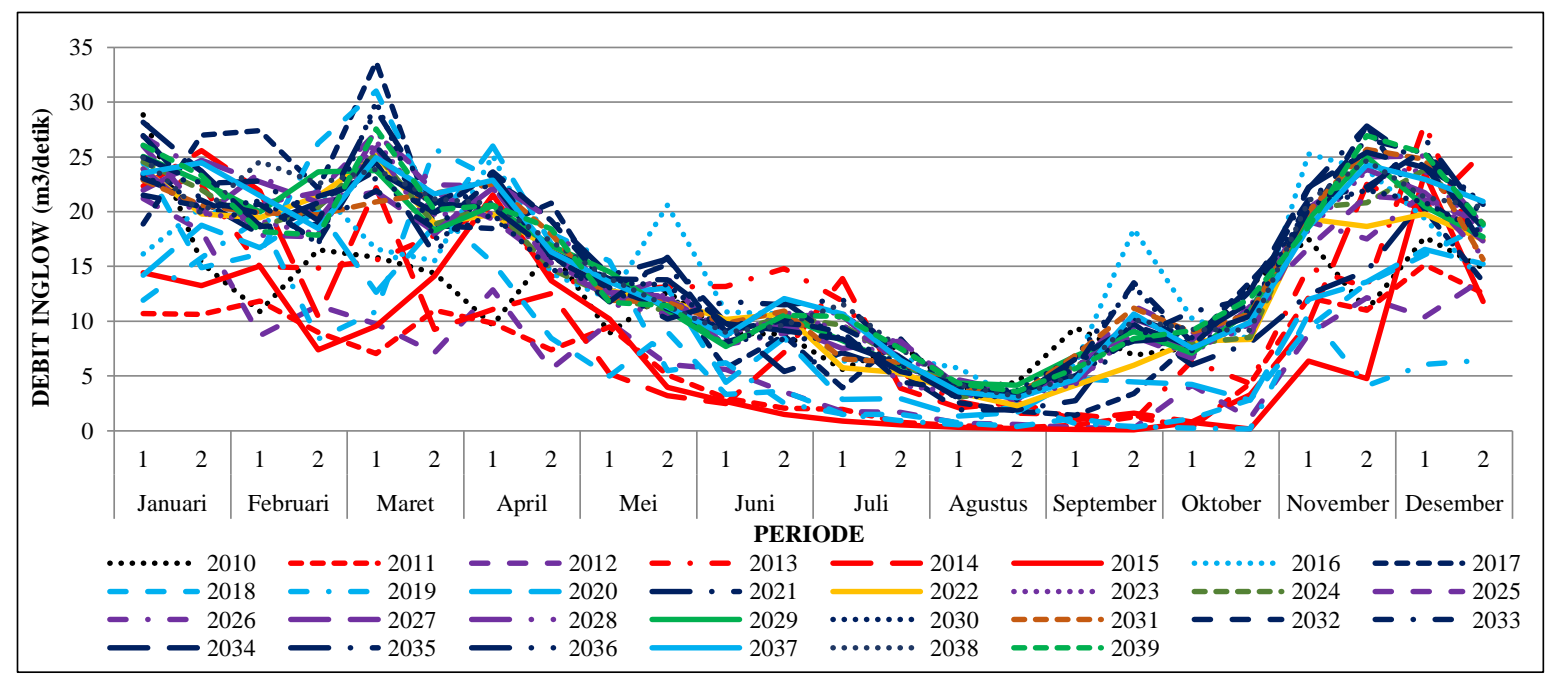

Gambar 4. Bangkitan Debit Inflow (2020-2039)

\section{Analisis Debit Kebutuhan Air Irigasi}

Beberapa hal yang perlu diperhatikan untuk analisis kebutuhan air irigasi adalah: a. Angka koefisien tanaman $(\mathrm{Kc})$ dengan varietas unggulan dan tanaman jagung (jenis palawija) berdasarkan Food and Agriculture Organization (Allen dkk, 2008). 
b. Jadwal awal masa tanam Desember 1 dan pola tanam berdasarkan existing yaitu padi-padi-palawija (BBWS Pemali Juana, 2020).

c. Daerah Irigasi Kedungsapen yang memiliki luas 1.595 ha (BSDA Seluna Juana, 2020)

Curah hujan efektif adalah curah hujan yang jatuh pada suatu daerah dan digunakan tanaman untuk pertumbuhannya ketika kehilangan air akibat evapotranspirasi tanaman (Morena, 2017).
Kemudian data yang diperlukan adalah hasil analisis sebelumnya, antara lain nilai $\mathrm{ET}_{0}$ dan angka koefisien yang digunakan berdasarkan kondisi lapangan. Berikut adalah hasil analisis debit kebutuhan air irigasi berdasarkan pola tanam existing, yang dapat dilihat pada Gambar 5.

Berdasarkan grafik diatas, dapat dilihat keseimbangan antara debit ketersediaan air dan kebutuhan air di DAS Randugunting. Terdapat bulan yang tidak dapat memenuhi kebutuhan air.

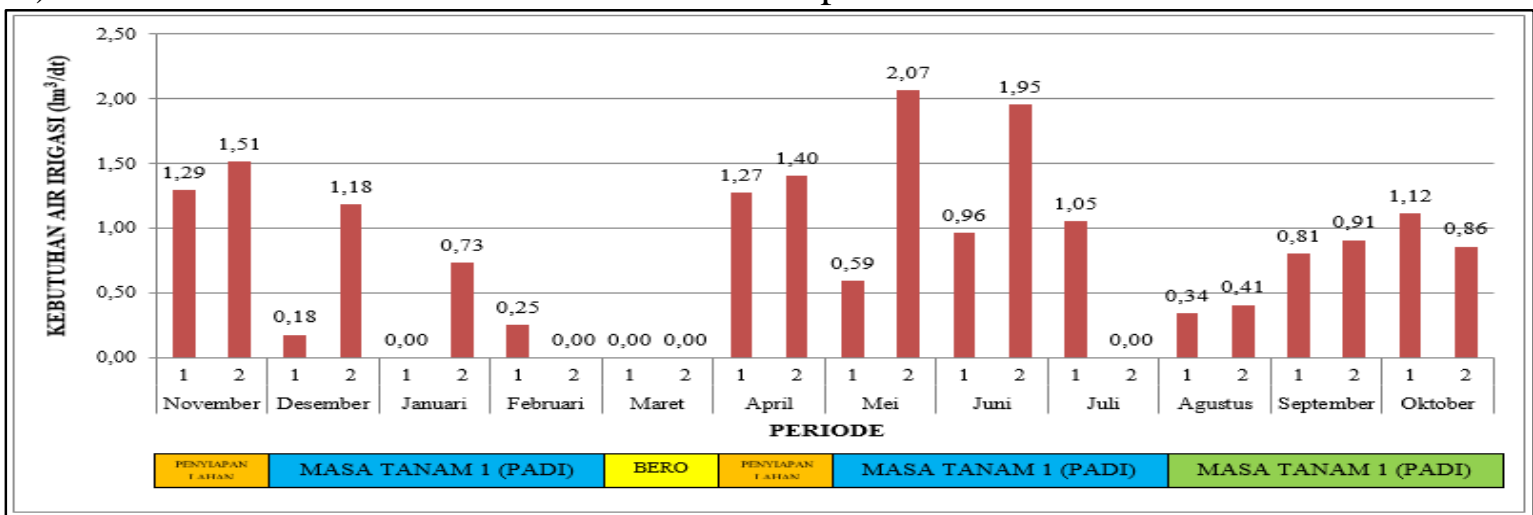

Gambar 5. Grafik Debit Kebutuhan Airi Irigasi Berdasarkan Pola Tanam Eksisting

Neraca Debit Air

Analisis ini akan menunjukan keseimbangan antara ketersediaan air dengan tingkat keandalan $80 \%(\mathrm{Q} 80 \%)$ dan kebutuhan air irigasi. Berikut adalah hasil grafik neraca debit air yang dapat dilihat pada Gambar 6.

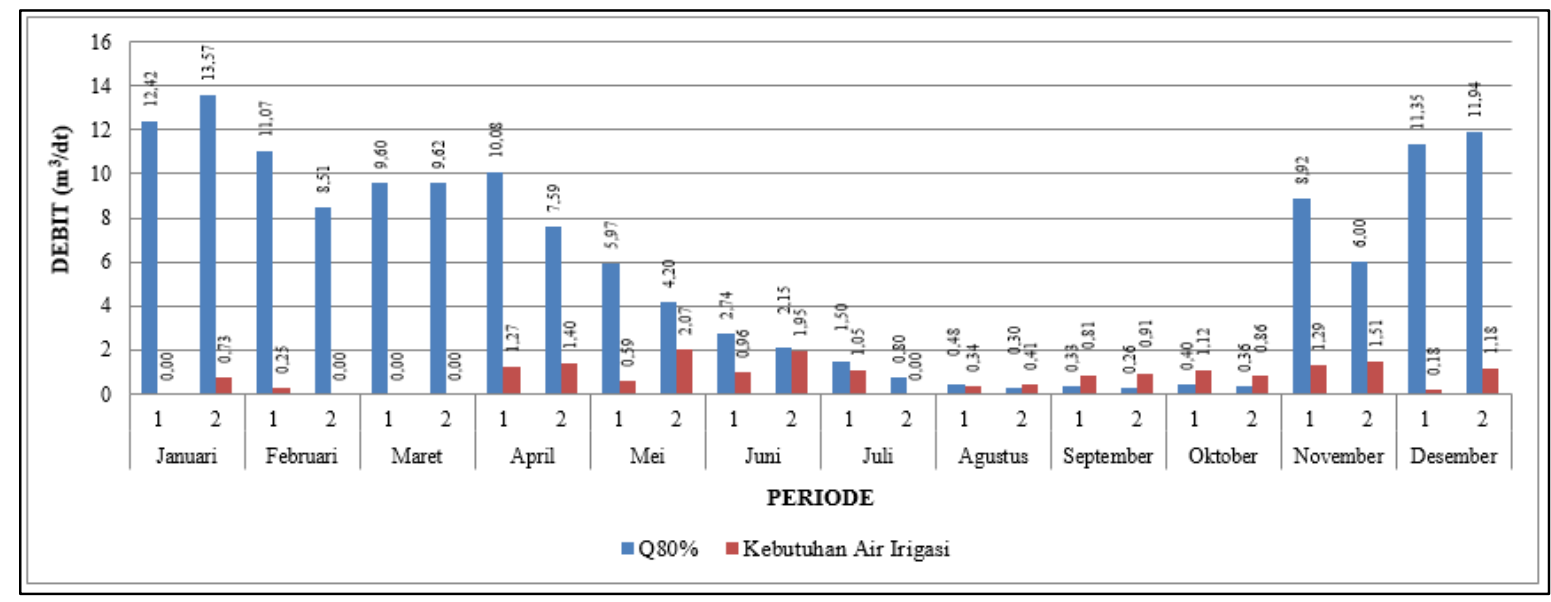

Gambar 6. Grafik Neraca Debit Ketersediaan Air (Q80\%) dan Kebutuhan Air Irigasi 
Simulasi Waduk Randugunting

Waduk adalah tempat dipermukaan bumi yang digunakan untuk menampung air saat musim penghujan dan mendistribusikannya saat musim kemarau (Risty, 2018). Sedangkan kebutuhan air untuk irigasi terus ada, oleh karena itu perlu adanya upaya memaksimalkan operasi waduk agar dapat memenuhi kebutuhan dengan maksimal. Pada simulasi ini menghasilkan persentase menjelaskan bahwa ada periode tanam yang tidak dapat terpenuhi dan terjadi kekurangan air ditampungan waduk.
Berikut merupakan langkah yang dilakukan untuk melakukan simulasi operasi waduk:

a. Kurva lengkung kapasitas waduk

Tahap simulasi ini diawali dengan mengetahui kapasitas tampungan waduk, untuk itu diperlukan data topografi tampungan untuk dibuat kurva lengkung kapasitas tampungan efektif. Setelah didapat volume tampungan, maka dibuat grafik lengkung kapasitas tampungan efektif, untuk hasil kurva dapat dilihat pada Gambar 7.

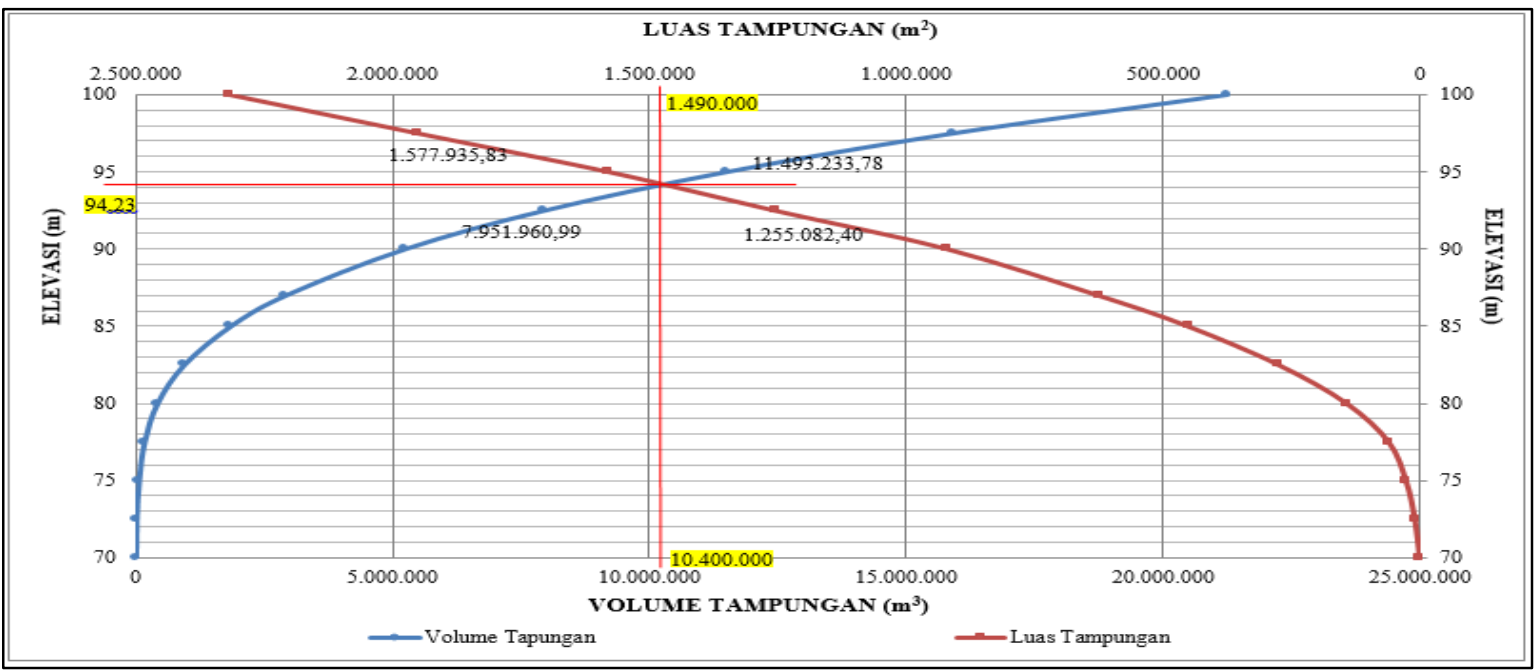

Gambar 7. Kurva Lengkung Kapasitas Waduk Randugunting

Berdasarkan grafik tersebut, didapat volume kapasitas efektif sebesar 10,4 juta $\mathrm{m}^{3}$ pada elevasi $+94,23 \mathrm{~m}$ dari permukaan dasar tampungan dan dengan luas segmen seluas 1,4 juta $\mathrm{m}^{3}$ yang dapat dilihat pada Gambar 4. Berdasarkan data Tim Perencana, volume tampungan mati yaitu 1,79 juta $\mathrm{m}^{3}$ pada elevasi $+84,87 \mathrm{~m}$ dari permukaan dasar tampungan.

b. Simulasi pengoperasian dengan pola tanam existing

Setelah diketahui volume tampungan efektif dan volume tampungan mati, berikutnya dilakukan simulasi dengan mengubah hasil analisis debit ketersediaan air menjadi volume inflow, debit kebutuhan air irigasi, nilai evaporasi dan rembesan menjadi volume outflow. Kemudian dari kedua volume tersebut, didapat nilai water balance dan volume air yang limpas (spill out).

Simulasi dengan pola tanam existing dilakukan dari tahun 2010 hingga tahun 2039, berikut adalah persentase hasil simulasi dari tahun 2010-2039 yang dapat dilihat pada Tabel 1 . 
Tabel 1. Persentase Periode Terlayani Tahun 2010-2039 (Pola Tanam Eksisting)

\begin{tabular}{|c|c|}
\hline Uraian & Nilai \\
\hline Periode berhasil & 719 \\
\hline Periode gagal & 1 \\
\hline Persentase berhasil (\%) & 99,86 \\
\hline Persentase gagal (\%) & 0,14 \\
\hline
\end{tabular}

Berdasarkan simulasi tersebut, terdapat satu periode gagal. Oleh sebab itu dilakukan pengoptimalan agar mendapat persentase $100 \%$ periode berhasil.

c. Optimalisasi pola operasi waduk Optimalisasi dilakukan dengan menggeser awal masa tanam satu periode dan menambah luas daerah irigasi hingga maksimal. Berikut hasilnya dapat dilihat pada Gambar 8.

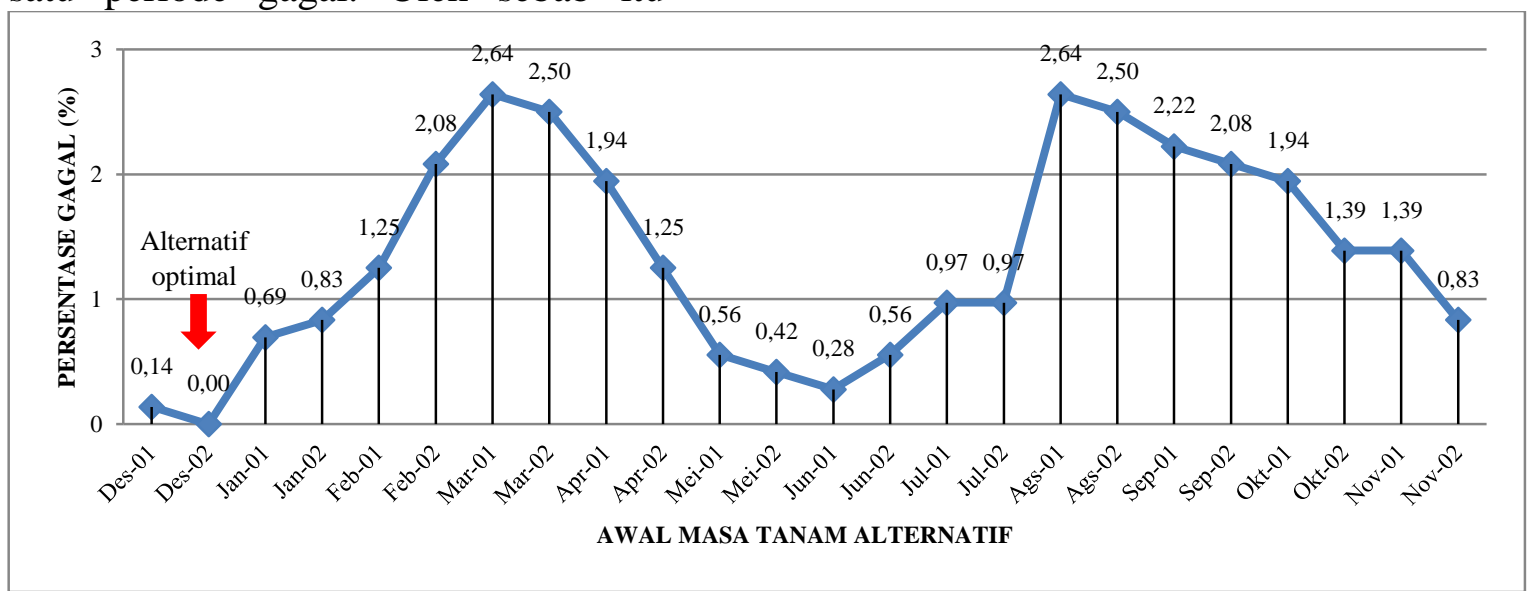

Gambar 8. Persentase Gagal Pola Operasi Alternatif

Berdasarkan simulasi dengan awal masa tanam alternatif, didapat satu alternatif dengan persentase keberhasilan $100 \%$ yaitu pada awal masa tanam Desember periode 2.

Setelah didapat pola operasi yang optimal, kemudian dilakukan optimalisasi dengan memperluas daerah layan DI Kedungsapen. Berikut adalah hasil optimalisasi awal masa tanam pertama (Desember periode 2) yang dapat dilihat pada Tabel 2 .
Tabel 2. Persentase Optimalisasi Awal Masa Tanam Pertama (Desember-02)

\begin{tabular}{|c|c|c|}
\hline $\begin{array}{c}\text { Luas DI } \\
\text { (hektare) }\end{array}$ & $\begin{array}{c}\text { Periode } \\
\text { Berhasil }\end{array}$ & $\begin{array}{c}\text { Persentase } \\
\text { Berhasil }\end{array}$ \\
\hline 1595 & 720 & $100 \%$ \\
\hline 1800 & 720 & $100 \%$ \\
\hline 2000 & 720 & $100 \%$ \\
\hline 2200 & 719 & $99.86 \%$ \\
\hline 2400 & 719 & $99.86 \%$ \\
\hline 2600 & 719 & $99.86 \%$ \\
\hline 2800 & 719 & $99.86 \%$ \\
\hline 3000 & 718 & $99.72 \%$ \\
\hline 3200 & 717 & $99.58 \%$ \\
\hline 3400 & 717 & $99.58 \%$ \\
\hline 3600 & 717 & $99.58 \%$ \\
\hline 3800 & 716 & $99.44 \%$ \\
\hline 4000 & 712 & $98.89 \%$ \\
\hline 4200 & 711 & $98.75 \%$ \\
\hline
\end{tabular}


Berdasarkan pengembangan DI Kedungsapen, didapat bahwa daerah irigasi dapat dikembangkan hingga luas 2.000 ha.

\section{Kesimpulan dan Saran Kesimpulan}

Hasil analisis dan perhitungan, maka dapat disimpulkan bahwa:

a. Nilai debit ketersediaan air terbesar $33,67 \mathrm{~m}^{3} /$ detik dan debit terkecil 0,07 $\mathrm{m}^{3} /$ detik.

b. Nilai debit kebutuhan air irigasi berdasarkan pola tanam existing terbesar 2,07 $\mathrm{m}^{3} /$ detik.

c. Kapasitas efektif tampungan waduk sebesar 10,4 juta $\mathrm{m}^{3}$ pada elevasi $+94,23$ m dan tampungan mati 1,7 juta $\mathrm{m}^{3}$ pada elevasi $+84,87 \mathrm{~m}$.

d. Hasil simulasi dengan pola tanam existing selama 30 tahun (2010-2039) persentase optimal sebesar 99,86\%. Dilakukan optimalisasi dengan menggeser awal masa tanam, pada bulan Desember periode 2 merupakan awal masa tanam yang optimal. Daerah Irigasi Kedungsapen masih dapat dikembangkan hingga 2.000 ha.

e. Didapat persamaan hasil trendline yang didapat dari hubungan antara persentase kegagalan dan perluasan daerah layan. Sehingga didapat persamaan $\mathrm{y}=8.10^{-6} \mathrm{x}^{3}-0,0001 \mathrm{x}^{2}+$ $0,0008 x-0,001$ dengan $R^{2}=0,9741$.

\section{Saran}

Adapun saran untuk penelitian ini yaitu:

a. Diperlukan pos stasiun hujan lebih dari dua pos stasiun, agar hasil lebih akurat.

b. Diperlukan data hujan harian lebih panjang, agar hasil lebih akurat.

c. Diperlukan data klimatologi lebih panjang, agar hasil lebih akurat. d. Diperlukan tinjauan mengenai sedimentasi.

e. Diperlukan tinjauan ulang mengenai analisis kebutuhan air baku, PLTA dan lainnya.

\section{DAFTAR PUSTAKA}

Allen dkk. (2008). "Irrigation and Drainage Paper No. 24". Rome : Food and Agriculture Organization. Diakses dari http://www.fao.org/tempref/SD/Reser ved/Agromet/PET/FAO_Irrigation_D rainage_Paper_56.pdf

Morena, Tika. 2017. "Studi Optimalisasi Pola Pengoperasian Waduk Bajulmati". Surabaya : Institut Teknologi Sepuluh Nopember http://repository.its.ac.id/45048/1/311 3100035-Undergraduate_Theses.pdf

Mythili, et al. 2013. "Study of Optimizing Techniques of Reservoir Operation". Journal Department of Civil Engineering KL University India. Diakses dari http://citeseerx.ist.psu.edu/viewdoc/d ownload?doi=10.1.1.676.9910\&rep= rep1\&type $=$ pdf

Risty, R. 2018. "Sumbang Hasil Erosi Lahan Terhadap Sedimentasi Pada Waduk (Studi Kasus Waduk Kedungombo)". Yogyakarta : Universitas Islam Indonesia https://dspace.uii.ac.id/handle/12345 6789/7974

SNI-7745-2012. "Tata Cara Perhitungan Evapotranspirasi Tanaman Acuan dengan Metode Penman-Monteith". Jakarta: Badan Standardisasi Nasional. Diakses dari 
http://docshare01.docshare.tips/files/

26867/268671893.pdf 